\title{
PEGylated Exendin-4, a Modified GLP-1 Analog Exhibits More Potent Cardioprotection than Its Unmodified Parent Molecule on a Dose to Dose Basis in a Murine Model of Myocardial Infarction
}

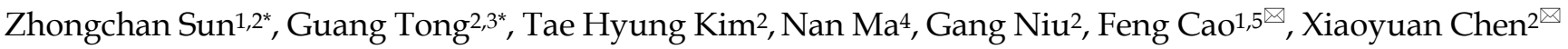 \\ 1. Department of Cardiology, Xijing Hospital, The Fourth Military Medical University, Xi'an, China 710032. \\ 2. Laboratory of Molecular Imaging and Nanomedicine (LOMIN), National Institute of Biomedical Imaging and Bioengineering (NIBIB), National \\ Institutes of Health (NIH), Bethesda, MD 20892-2281, USA. \\ 3. Department of Cardiovascular Surgery, General Hospital of Guangzhou Military Command, Guangzhou 510010, China; \\ 4. Department of Ophthalmology, Tangdu Hospital, Fourth Military Medical University, Xi'an 710038, China; \\ 5. Department of Cardiology, Chinese PLA General Hospital, Beijing, 100853, China. \\ *Zhongchan Sun and Guang Tong contributed equally to this article.
}

$\bowtie$ Corresponding authors: Feng Cao, wind8828@gmail.com; Gang Niu, gang.niu@nih.gov; Xiaoyuan Chen, shawn.chen@nih.gov.

(c) Ivyspring International Publisher. This is an open-access article distributed under the terms of the Creative Commons License (http://creativecommons.org/ licenses/by-nc-nd/3.0/). Reproduction is permitted for personal, noncommercial use, provided that the article is in whole, unmodified, and properly cited.

Received: 2014.07.31; Accepted: 2014.11.14; Published: 2015.01.01

\begin{abstract}
A Site-specifically PEGylated exendin-4 (denoted as PEG-Ex4) is an exendin-4 (denoted as Ex4) analog we developed by site-specific PEGylation of exendin-4 with a high molecular weight trimeric poly(ethylene glycol) (tPEG). It has been shown to possess prolonged half-life in vivo with similar receptor binding affinity compared to unmodified exendin- 4 by our previous work. This study is sought to test whether PEG-Ex4 is suitable for treating myocardial infarction (MI). In the MI model, PEG-Ex 4 was administered every 3 days while equivalent amount of Ex 4 was administered every 3 days or twice daily. Animal survival rate, heart function, remodeling and neoangiogenesis were evaluated and compared. Tube formation was examined in endothelial cells. In addition, Western blotting and histology were performed to determine the markers of cardiac hypertrophy and angiogenesis and to explore the possible molecular mechanism involved. PEG-Ex4 and Ex4 showed comparable binding affinity to GLP-1 receptor. In MI mice, PEG-Ex4 given at 3 days interval achieved similar extent of protection as Ex4 given twice daily, while Ex4 given at 3 days interval failed to produce protection. PEG-Ex4 elevated endothelial tube formation in vitro and capillary density in the border area of MI. PEG-Ex4 increased Akt activity and VEGF production in a GLP-IR dependent manner in endothelial cells and antagonism of GLP-1R, Akt or VEGF abolished the protection of PEG-Ex4 in the MI model. PEG-Ex4 is a potent long-acting GLP-1 receptor agonist for the treatment of chronic heart disease. Its protection might be attributed to enhanced angiogenesis mediated by the activation of Akt and VEGF.
\end{abstract}

Key words: Exendin-4, PEGylation, cardioprotection, Angiogenesis, myocardial infarction.

\section{Introduction}

The glucagon-like peptide-1 (GLP-1) is a hormone derived from the transcription product of the proglucagon gene that is secreted from intestinal endocrine $L$ cells in response to nutrients $[1,2]$.
GLP-1(7-36) exerts incretin-like actions stimulating insulin secretion in a glucose-dependent manner when interacting with its receptor (GLP-1R) on $\beta$ islets [3]. GLP-1R is also expressed in many other cell types 
$[4,5]$, including cardiomyocytes [6], endothelial cells [7] etc. Recently, GLP-1 and its analogs were brought under the spotlight for their potent therapeutic potential for ischemic heart disease [4, 8], namely myocardial ischemia/reperfusion injury [8] and chronic heart failure secondary to myocardial infarction (MI) [6]. However, clinical application of GLP-1 was hindered by its short half-life due to the rapid breakdown by dipeptidyl peptidase-4 (DPP4). Currently, exendin-4 (denoted as Ex4) [9], a GLP-1 analog, is approved by the Food and Drug Administration (FDA) for glucose control in patients with type 2 diabetes mellitus. Although it has a relatively longer half-life (60 to $90 \mathrm{~min}$ ) than GLP-1 (a few minutes), it still requires to be injected twice daily to maintain continuous effective blood drug concentration. Attempts have been made to prolong the half-life of GLP-1 and its analog in vivo [10-12]. DPP4 inhibition has been shown to elevate endogenous GLP-1 level [13] but modification of artificial GLP-1 analog seems to be a more promising strategy as it is independent of endogenous GLP-1 synthesis. We previously reported a long circulating exendin-4 (C40-tPEG-Ex4-Cys, denoted as PEG-Ex4) through C-terminal PEGylation of exendin-4 with a high-molecular-weight trimeric poly (ethylene glycol) (tPEG, M.W. = 50 k) [14]. PEG-Ex4 was found to have greater blood circulating $t_{1 / 2}$ and $\mathrm{AUC}_{\mathrm{inf}}$ values than the native Ex4, thus a more potent anti-type 2 diabetic agent. However, whether the long half-life of this molecule can be translated into therapeutic benefit in chronic ischemic heart disease has never been tested. In the present study, we hypothesize that PEG-Ex4 with prolonged half-life in vivo can achieve better cardioprotection effect than exendin- 4 .

\section{Materials and Methods}

\section{Preparation and Characterization of PEGylated Exendin-4}

Exendin- 4 and activated trimeric PEG were used for the preparation of C-terminal PEGylated exendin-4, which has been shown to have superior longevity and optimal GLP-1 receptor binding. Briefly, mPEG-MAL (3-arm branched PEG- $\left(\mathrm{CH}_{2}\right)_{3} \mathrm{NHCO}$ $\left(\mathrm{CH}_{2}\right)_{2}$-MAL, $\mathrm{Mw}$ 50,000, purchased from NOF America Corporation, $1.6 \mathrm{mg} / \mathrm{mL}$ in DMSO containing $0.3 \%$ TEA) was reacted with exendin-4 (10 $\mathrm{mg} / \mathrm{mL}$ in DMSO containing $0.3 \%$ TEA) with an exendin-4/mPEG-MAL at a molar ratio of 2 at room temperature for $1 \mathrm{~h}$. The reaction was then quenched by adding $100 \mu \mathrm{L}$ of stop solution (deionized water containing 1\% TFA). HPLC purification and yield calculations were also performed as previously described [14].

\section{In vitro Biological Activity Testing (cell binding} assay)

The biological activities of PEG-Ex4 and Ex4 were determined using a competitive receptor-binding assay in the steady state using INS-1 cells as previously described [15]. INS-1 cell line was chosen for its high expression of glucagon-like peptide-1 receptor (GLP-1R). GLP-1 peptide labeled with ${ }^{125 I}$ is able to specifically bind to GLP-1R of INS-1 cells in vitro. By mean of competition for GLP-1R, the effectiveness of either PEG-Ex4 or its parental compound Ex4 specifically binding to GLP-1R can be determined with the help of measurement and analysis of ${ }^{125} \mathrm{I}$ radioactivity. Potent binding of PEG-Ex4 to GLP-1R is fundamental for the cardioprotective benefits of PEG-Ex4, laying the basis for the following in vivo cardiac studies.

Briefly, INS-1 cells were seeded in 12-well plates at $5 \times 10^{5}$ cells per well, washed twice with binding buffer $\left(120 \mathrm{mM} \mathrm{NaCl}, 1.2 \mathrm{mM} \mathrm{MgSO}_{4}, 13 \mathrm{mM}\right.$ sodium acetate, $5 \mathrm{mM} \mathrm{KCl}, 1.2 \mathrm{~g} / \mathrm{L}$ Tris, $2 \mathrm{~g} / \mathrm{L}$ bovine serum albumin (BSA), and $1.8 \mathrm{~g} / \mathrm{L}$ glucose, $\mathrm{pH} 7.6$ ), added PEG-Ex4 or Ex4 (final concentrations: $0.001-1000 \mathrm{nM}$ ) containing $30 \mathrm{pM}$ of ${ }^{125}$ I-exendin-4(9-39) (PerkinElmer, Boston, MA), and then incubated for $2 \mathrm{~h}$ at room temperature. The plates were washed 3 times with chilled PBS containing $1 \mathrm{mg} / \mathrm{mL}$ of BSA. Cells were then lysed with cell lysis buffer $(0.5 \mathrm{~N} \mathrm{NaOH}$ containing 1\% SDS) for $15 \mathrm{~min}$, and ${ }^{125}$ I radioactivity was measured using a $\gamma$ counter (GMI, Inc, Ramsey, $\mathrm{MN})$.

\section{Animal Model Preparation}

All animal experiments were performed in adherence with the National Institutes of Health (NIH) guidelines on the use of laboratory animals and were approved by the NIH Clinical Center Animal Care and Use Committee. To establish myocardial infarction (MI) in C57/BL6 mice, adult male C57/BL6 mice were anesthetized with $2 \%$ isoflurane in oxygen delivered at a flow of $1.0 \mathrm{~L} / \mathrm{min}$. MI was induced via permanent left anterior descending coronary artery (LAD) ligation as previously described [15]. In sham-operated control mice (sham), the same surgical procedures were performed except that the suture placed under the LAD was not tied.

\section{Experimental Protocols}

In order to evaluate the therapeutic potential of PEG-Ex4, animals were exposed to MI injury. Two days after surgery, MI induction was confirmed by echocardiography. Only the mice with ejection fraction (EF) between $30 \%$ and $60 \%$ were recognized as a successful induction of MI and included in the following studies. Animals were then randomized into 
the following groups: sham-operation group $(\mathrm{n}=6)$, $\mathrm{MI}+$ vehicle $(\mathrm{n}=15), \mathrm{MI}+$ PEG-Ex4 $(\mathrm{n}=20 ; 675$ $\mu \mathrm{g} / \mathrm{kg}$ PEG-Ex4 which carries $50 \mu \mathrm{g} / \mathrm{kg}$ Ex4) was administered IV bolus every 3 days. In our previous report, PEG-Ex4 administered at this time interval was able to achieve stable blood drug concentration, and this group is labeled as PEG Ex4-P1), Two groups treated with Exendin- 4 were also included as positive control. MI + Ex4 (n = 20); in this group $50 \mu \mathrm{g} / \mathrm{kg}$ of Ex4 were administered IV bolus every 3 days as Ex4-P1); MI + Ex4 ( $=20)$; in this group, $50 \mu \mathrm{g} / \mathrm{kg}$ of Ex4 was administered IV bolus twice daily and labeled as Ex4-P2. Animals underwent various imaging scans in vivo including echocardiography, small animal PET as described in the following methods before being euthanized for histological examination at day 30 since the onset of the model.

For the assessment of molecular pathways involved in myocardial protection, three additional groups were included: MI+ PEG-Ex4 + exendin(9-39) (GLP-1 receptor antagonist, $0.5 \mathrm{mg} / \mathrm{kg} /$ day, IV, $\mathrm{n}=$ 10); MI + PEG-Ex4 + LY294002 ( $\mathrm{n}=12$, Akt inhibitor, $1.5 \mathrm{mg} / \mathrm{kg} /$ day, IP); MI + PEG-Ex4 + CBO-P11 ( $\mathrm{n}=$ 12, VEGF inhibitor, $0.5 \mathrm{mg} / \mathrm{kg} /$ day, IP). Myocardial tissues were harvested for further analysis at molecular levels.

\section{Echocardiography}

Transthoracic echocardiography was performed preoperatively (day 0 , baseline) and at the indicated time points after MI induction (day 2, 9, 16, 23, and 30 ). Data acquisition was performed on lightly anesthetized animals using inhalation of $1 \%$ isoflurane in $100 \%$ oxygen mixture through a nose cone. Both two-dimensional and M-mode echocardiographies were obtained with a $15-\mathrm{MHz}$ linear transducer (VisualSonics Vevo 2100, Toronto, ON, Canada) [16]. Cardiac dimensions such as left ventricular end diastolic diameter (LVEDD) and left ventricular end systolic diameter (LVESD) were measured in short axis view at the papillary muscle level from M-mode tracing. All the measurements were performed in a blinded manner and represent the mean of 5 consecutive cardiac cycles. Cardiac contractile function represented by left ventricular fraction shortening (LVFS) was calculated by computer algorithms.

\section{Histological analysis}

Mice were euthanized at day 30 for histological examination. Hearts were fixed with $4 \%$ paraformaldehyde, then the heart tissue below the ligation site were sectioned transversely into 5 slices, with one mid myocardium slice, 2 slices above and 2 slices below. All 5 slices were embedded in paraffin, and transversely sectioned (6 $\mu \mathrm{m}$ thick) for histological stain- ing. For immunofluorescence staining, cryosections were used. Five sections from each embedded heart were mounted upon glass slides, and stained with Masson trichrome (for fibrosis determination), antibody against CD31 (for capillary density), or antibody against a-smooth muscle actin (a-SMA, for arteriolar density). Myocyte/fibrosis ratio (left ventricular free wall), cardiac collagen deposit (remote non-infarct area), and capillary/arteriolar density (infarct border zone) were determined as previously reported.

\section{Tube formation assay}

Tube formation assay was performed using human umbilical vein endothelial cells (HUVECs) for in vitro neo-angiogenesis evaluation. Matrigel (growth factor reduced, BD Biosciences, $100 \mu \mathrm{l}$ ) was added to each well of a 48 -well plate, and polymerized at $37^{\circ} \mathrm{C}$ for $1 \mathrm{~h}$. Human umbilical vein endothelial cells (HUVECs, $1 \times 10^{4}$ ) were then seeded onto Matrigel and cultured in endothelial cell basal medium-2 with EGM-2 Bullet Kit. After $1 \mathrm{~h}$ culture, PEG-Ex4 or Ex4 was added into medium with final concentration of 100 nM. Exendin-4 (9-39) (200 nM), LY294002 (30 $\mu \mathrm{M})$ and CBO-P11 $(2 \mu \mathrm{M})$ were added to the culture medium for respective inhibition effects. After an additional $6 \mathrm{~h}$ culture, tube length was quantified via IP Lab 4.0 image analysis software.

\section{Western blot analysis}

Proteins were extracted from mouse heart tissue or HUVECs and were lysed in RIPA buffer. Protein concentrations were measured using the BCA protein assay. Proteins were separated by electrophoresis on SDS-PAGE and transferred onto a nitrocellulose membrane. After being blocked with 5\% milk, the immunoblots were probed with the primary anti-pAkt, anti-pAMPK, anti-VEGF and anti- $\beta$-actin (Abcam, Cambridge, UK) overnight at $4^{\circ} \mathrm{C}$ followed by incubation with the corresponding secondary antibodies. The blot was developed with a chemi-luminescence substrate solution (Pierce) and exposed to X-ray film. pAkt or pAMPK immunoblots were then stripped with strip buffer at $50{ }^{\circ} \mathrm{C}$ for 30 min and reblotted for total Akt or AMPK.

\section{Statistical Analysis}

GraphPad Prism-5 statistic software (La Jolla, CA) was used for all data analysis. All values were presented as the mean \pm SEM. One-way ANOVA was conducted across all investigated groups before post hoc tests with Bonferroni correction and all 2-group comparisons were made. Survival data were analyzed by the Kaplan-Meier method followed by the log rank test. Values of $\mathrm{P}<0.05$ were considered statistically significant. 

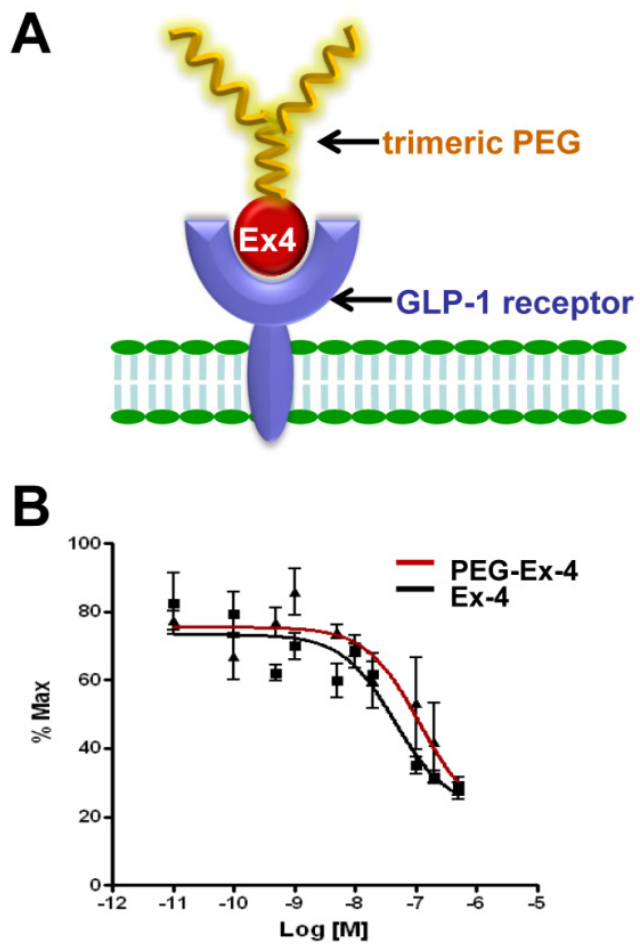

Figure 1. A, Schematic structure of C40-tPEG-Ex4-Cys (PEG-Ex4). B, In vitro biological activity of PEG-Ex4 and Ex4 in INS-1 cells. PEG-Ex4 demonstrates similar binding affinity as Ex4 to GLP-1 receptors on INS-1 cells.

\section{Results}

\section{PEGylated Exendin-4 Has Similar Binding Af- finity to GLP-1R as Exendin-4}

C-terminal specific PEG Exendin-4 using trimeric PEG (C40-tPEG-Ex4-Cys) was synthesized as described before and its schematic structure was shown in Figure 1A. The receptor-binding affinities of PEG-Ex4 and Ex4 were examined in INS-1 cells, which express high level of GLP-1 receptor. As illustrated in Figure 1B, trimeric PEG modification slightly decreased receptor binding affinity of PEG-Ex4 $\left(\mathrm{IC}_{50}=\right.$ $112.0 \mathrm{nM})$, compared to the parental peptide Ex4 $\left(\mathrm{IC}_{50}\right.$ $=44.82 \mathrm{nM}$ ), suggesting that the conjugation of a trimeric PEG had only minor effect on exendin- 4 binding affinity to its specific receptor GLP-1R.

\section{PEGylated Exendin-4 is Much Longer-lasting than Exendin-4 in Improving Survival and Preserving Cardiac Function after MI}

Administration of PEG-Ex4 every 3 days produced similar extent of survival benefit as Ex4 twice daily (Fig. 2A). However, Ex4 administered at the same dose and frequency as PEG-Ex4 failed to increase survival. Cardiac function was examined with echocardiography. As shown in Figure 2B. Ex4 (Ex4-P1) failed to produce significant improvement of cardiac function, as compared to vehicle (MI), at 4 weeks after the initiation of treatment. Nevertheless,
PEG-Ex4 treatment (PEG Ex4-P1) was able to significantly restore cardiac function as evidenced by higher LVFS values (Fig. 2C), compared to MI and Ex4-P1 groups. Meanwhile, Ex4-P2, in which Ex4 was given twice daily rather than every 3 days, produced benefit in cardiac function preservation comparable to PEG-Ex4 group. In other words, PEG-Ex4 is much longer-lasting than Ex4 in improving survival and preserving cardiac function after MI.

\section{PEGylated Exendin-4 Alleviates LV Cardiac Remodeling}

Cardiac remodeling was examined by several means given the critical role remodeling plays in post-ischemic cardiac dysfunction. Indexes of LV enlargement were determined by echocardiography. At 30 days after MI, both PEG Ex4-P1 and Ex4-P2 preserved LV end-diastolic (LVEDD) and LV end-systolic (LVESD) dimension (Fig. 3A, B) to a similar extent. They also reduced heart size and shrank left ventricular dimensions as demonstrated by echocardiography (Fig. 3A, B) and H\&E staining (Fig. 3C). On the other hand, Ex4-P1 failed to reduce LV dimensions and heart size. H\&E staining also showed much enlarged cardiomyocytes in the remote area of ischemic heart in both MI control and Ex4-P1 groups, which was ameliorated by PEG Ex4-P1 and Ex4-P2 (Fig. 3D, E). Cardiac hypertrophy in the remote area is one of the most important features of cardiac remodeling. As shown in Figure 3F, higher heart weight/body weight (HW/BW) ratio was found in both the MI control and Ex4-P1 groups, than that in Ex4-P2 and PEG Ex4-P1groups.

Fibrosis was examined ex vivo. After MI, the necrotic myocardial tissue is replaced by fibrosis formation over time, which also accounts for the cardiac remodeling post MI. PEG Ex4-P1 and Ex4-P2 dramatically decreased the fibrosis ratio of left ventricle (Fig. 3G, H). Moreover, PEG Ex4-P1 and Ex4-P2 were able to significantly attenuate interstitial fibrosis in the border area of ischemic myocardium (Fig. 3G, I). However, no significant difference was found between the vehicle and Ex4-P1 groups.

\section{PEGylated Exendin-4 Enhances Myocardial Angiogenesis in Border Zone of Ischemic My- ocardium}

A key determinant of functional cardiac compensation post MI is angiogenesis. Insufficient angiogenesis has recently been recognized as a driver for heart failure. Having demonstrated that PEG-Ex4 is a long-acting peptide, which potently enhances survival and alleviates adverse remodeling. Ex vivo histological examination was conducted to evaluate neoangiogenesis. In the border zone of MI, PEG Ex4-P1 
and Ex4-P2 treated groups had significantly higher myocardial capillary density than the vehicle and Ex4-P1 groups 30 days after $\mathrm{MI}$ as evidenced by immunostaining of CD31 (Fig. 4A, 4C), an endothelial cells marker. Density of functional small artery was examined by a-smooth muscle actin (a-SMA) staining. As illustrated in Figure 4B, PEG Ex4-P1 treatment markedly increased the a-SMA-positive arterial density (Fig. 4D) in the border zone, which is comparable with Ex4-P2 treatment, suggesting successful induction of mature vessel formation after MI. Nevertheless, these observations were not found in the Ex4-P1 group.

\section{GLP-1R/Akt/VEGF Pathway Mediates the Di- rect Pro-angiogenic Activity of PEG Exendin-4}

Endothelial cells are essential in angiogenesis and post-ischemic cardiac repair. To directly investigate the effect of PEG-Ex4 on endothelial cells, we undertook an in vitro endothelial cell tube formation assay. Both PEG-Ex4 and Ex4 significantly enhanced tube formation of HUVEC cells (Fig. 5A). This result indicates that GLP-1R activation by PEG-Ex4 produces strong proangiogenic effects on endothelial cells.

To determine the molecular signaling mechanisms responsible for increased angiogenesis induced by PEG-Ex4 treatment, several critical mediators and cytokines requisite for angiogenesis were assessed.

A

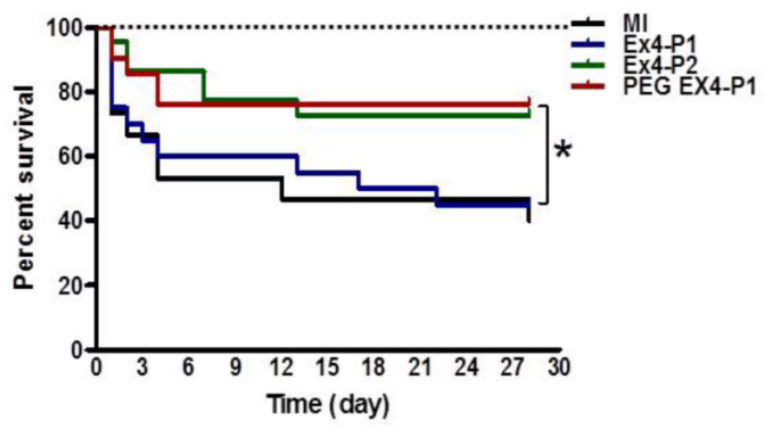

C

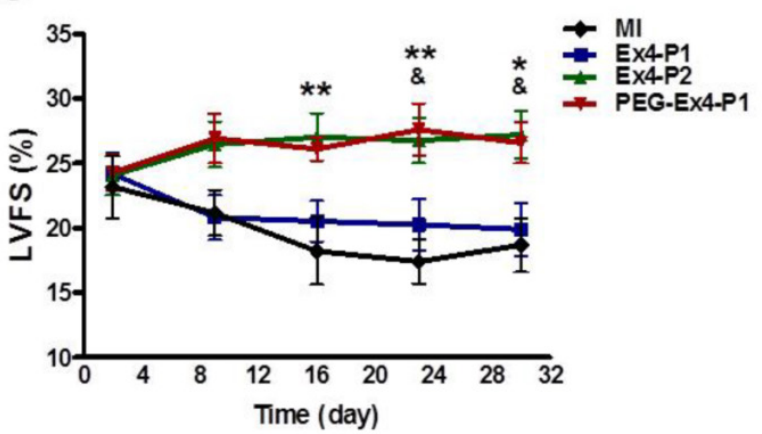

AMPK, Akt and VEGF were examined for their well-established roles in angiogenesis. PEG-Ex4 did not increase AMPK activity (Fig. 5B, D), however, it did enhance Akt phosphorylation (Fig. 5B, C) and vascular endothelial growth factor (VEGF) expression (Fig. 5B, E).

Having demonstrated that PEG-Ex4 increased angiogenesis, Akt phosphorylation, VEGF expression in vivo and stimulated tube formation of endothelial cells in vitro, we further hypothesized that PEG-Ex4 stimulates angiogenesis through direct activation of GLP-1R/Akt/VEGF axis in endothelial cells. To confirm this, GLP-1R antagonist exendin-4(9-39), Akt inhibitor LY294002 or VEGF specific inhibitor CBO-P11 was added into culture medium of HUVECs together with PEG-Ex4. Both phosphorylated Akt (p-Akt) and VEGF level were significantly elevated by PEG-Ex4 treatment (Fig. 6B). However, co-treatment with either exendin-4(9-39) or LY294002 abolished the effect of PEG-Ex4 on p-Akt (Fig. 6B, D) and VEGF expression (Fig. 6B, E). Moreover, co-treatment with either exendin-4(9-39) or LY294002 could also inhibit tube formation induced by PEG-Ex4, which was also observed in CBO-P11 co-treatment group (Fig. 6A, C). Taken together, these results suggest that PEG-Ex4 stimulates tube formation through the activation of GLP-1R/Akt/VEGF pathway.

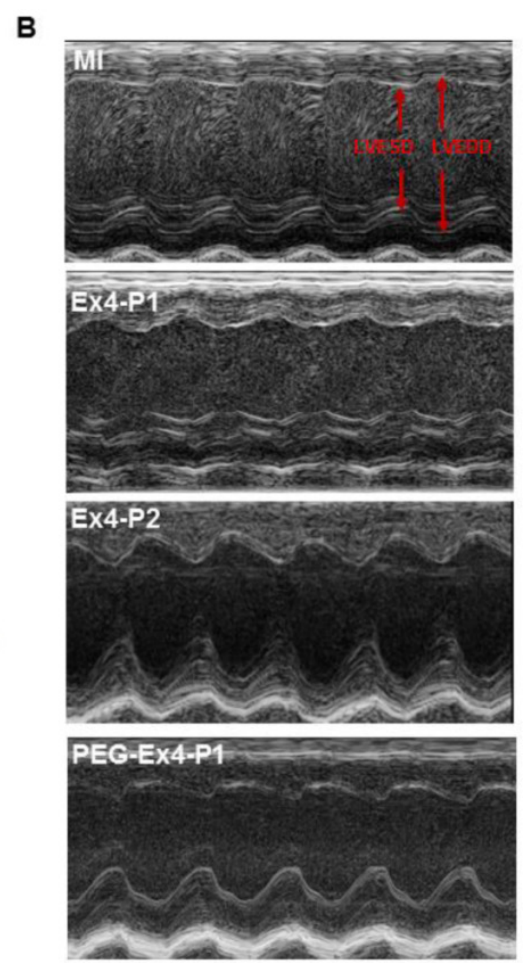

Figure 2. C40-tPEG-Ex4-Cys (PEG-Ex4) improves survival and restores left ventricular cardiac function after MI. Mice were subjected to MI and treated with PEG Ex4-P1, Ex4-P1 or Ex4-P2. The survival and left ventricular cardiac function were determined at different time points after operation. A, Kaplan-Meier survival curve. $\mathrm{B}-\mathrm{C}$, Echocardiographic analysis. LVFS, LV fractional shortening; MI, myocardial infarction; Ex4-P1, Exendin-4 treatment, protocol 1 (50 $\mu$ g/kg of Ex4, IV bolus every

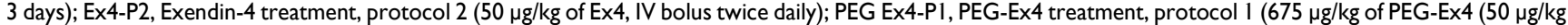
equivalent of Ex4), IV bolus every 3 days). ${ }^{*} P<0.05$ vs. MI, ${ }^{* *} P<0.01$ vs. MI; \& $P<0.05$ vs. Ex4-P1. 
A

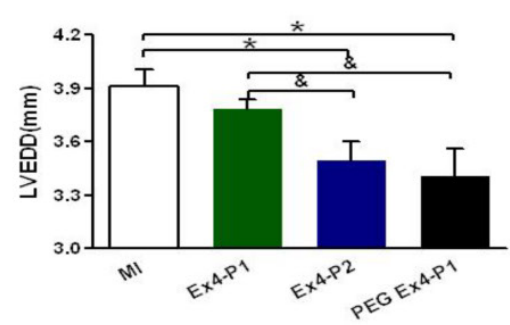

C
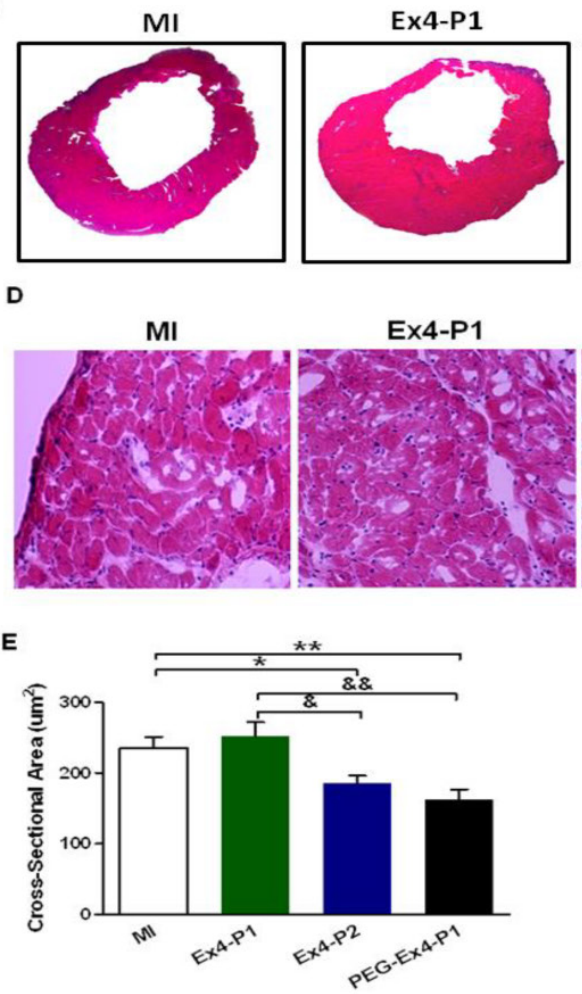

G
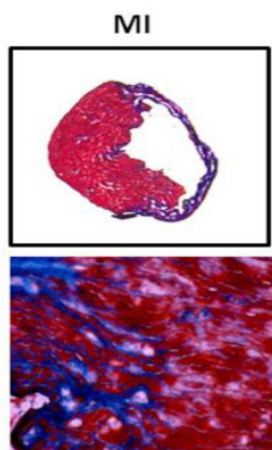

H

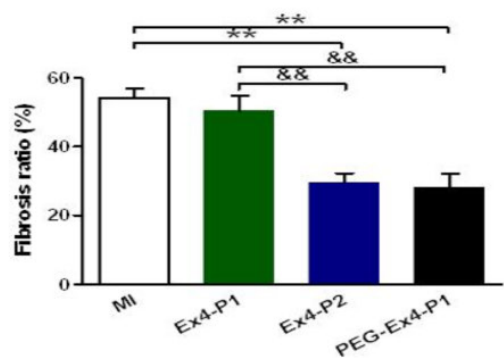

B
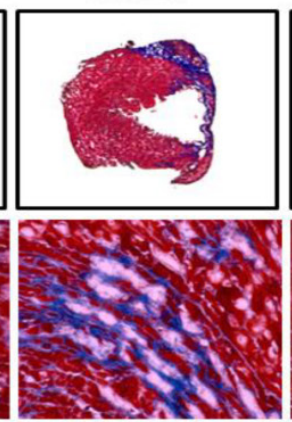
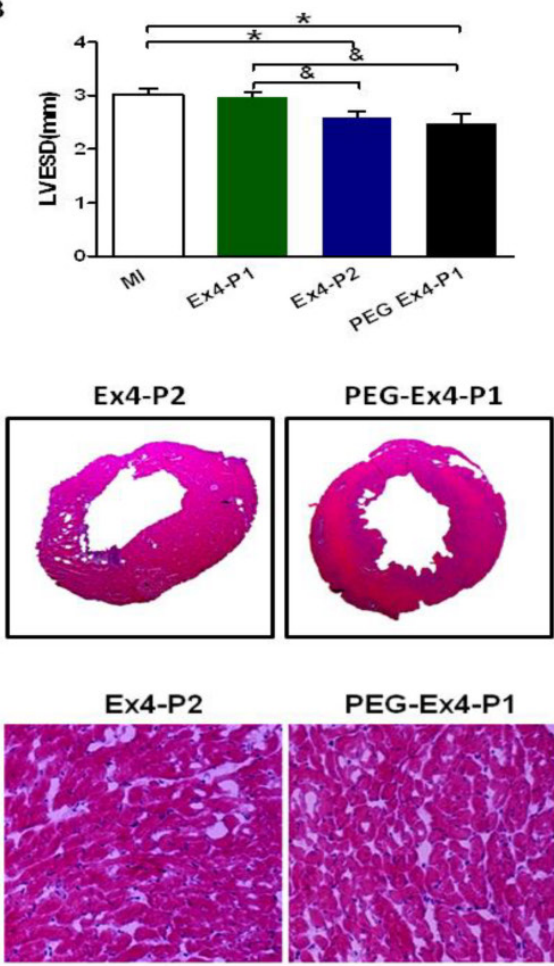

PEG-EX4-P1

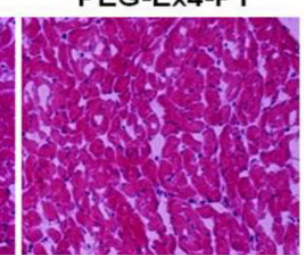

$\mathbf{F}$

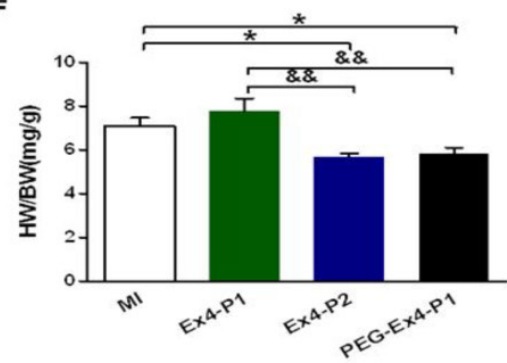

Ex4-P2

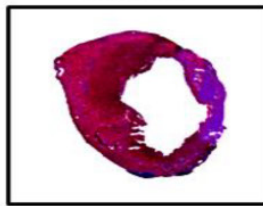

PEG-Ex4-P1
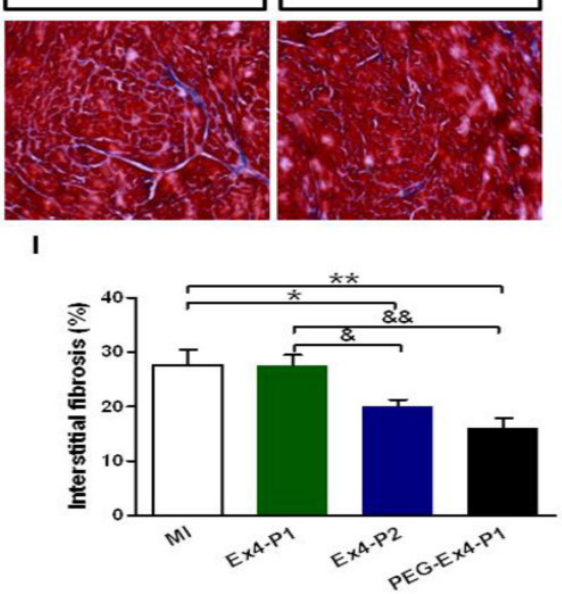

Figure 3. C40-tPEG-Ex4-Cys (PEG-Ex4) prevents left ventricular (LV) cardiac remodeling after myocardial infarction (MI). A and B, LV end-diastolic and end-systolic dimensions (LVEDD and LVESD) from echocardiographic analysis. $C, H \& E$ staining of left ventricle. $D$ and $E$, Cross sectional areas ( $\mu m^{2}$ ) remote to ischemia. $F, H_{\text {eart }}$ weight to body weight (HW/BW) (mg/g) ratio. G, Cardiac Masson's trichrome staining. H, Fibrosis ratio. I, Interstitial fibrosis. ${ }^{*} P<0.05$ vs. MI, ${ }^{* *} P<0.01$ vs. Ml; $\& P<$ 0.05 vs. Ex4-PI, \&\&P< 0.01 vs. Ex4-P1. 
A
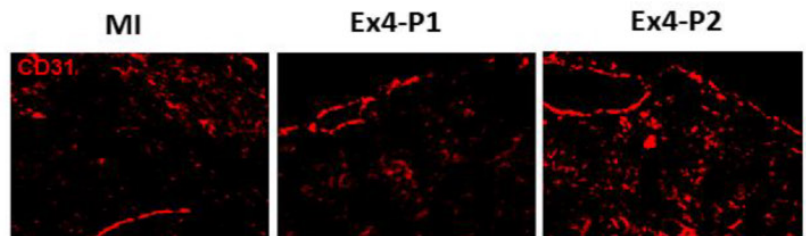

PEG-Ex4-P1
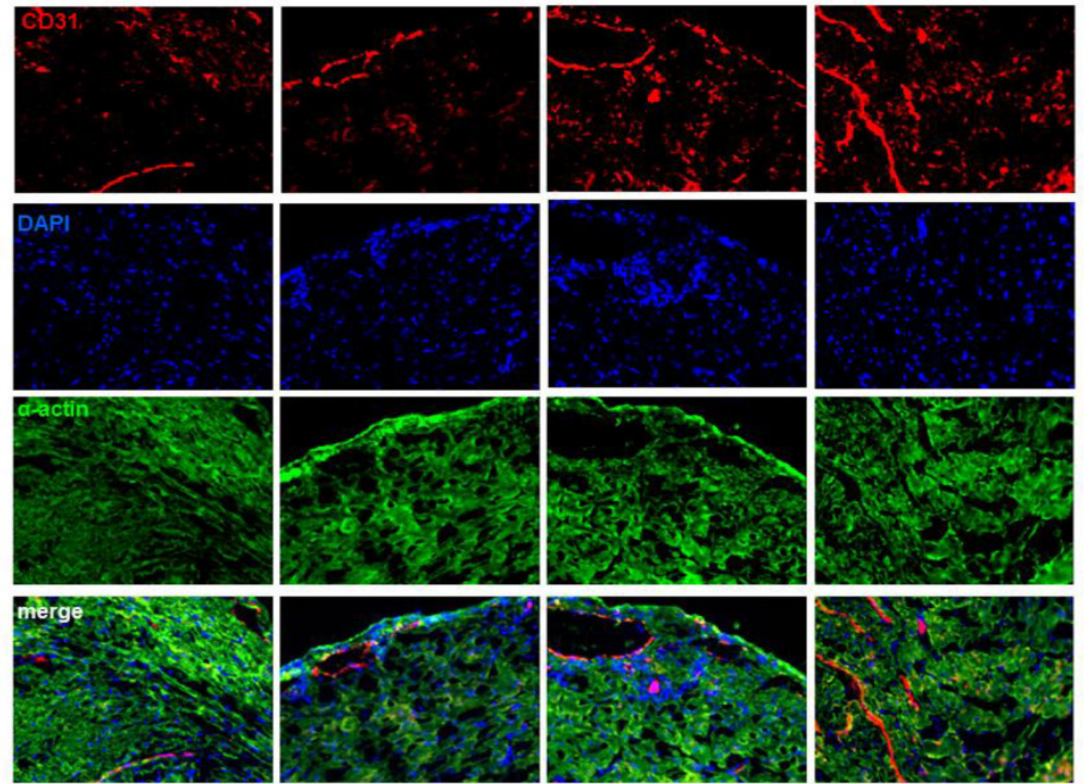

B

MI
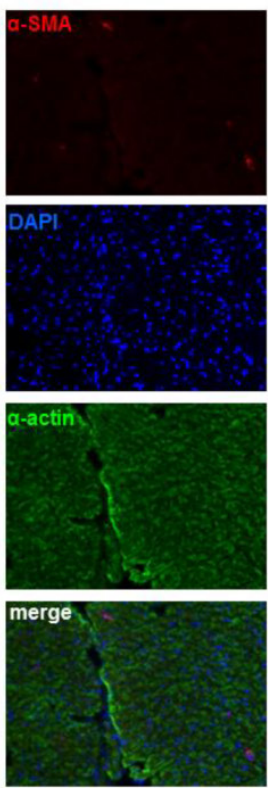

C
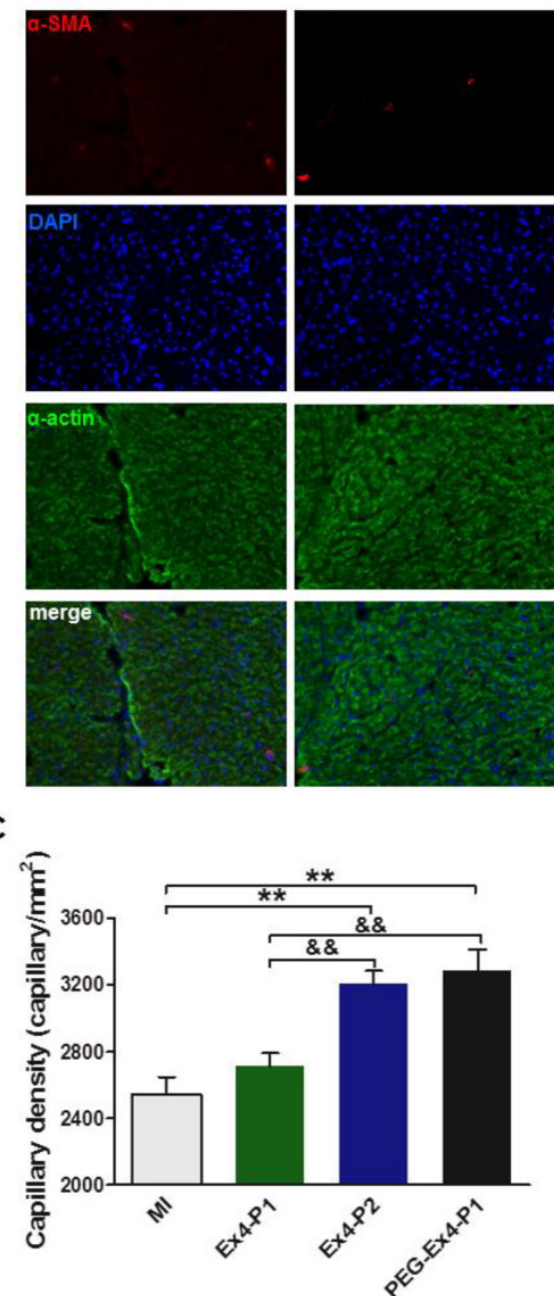
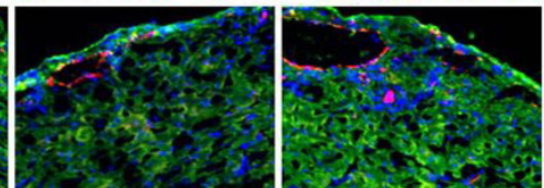

Ex4-P2
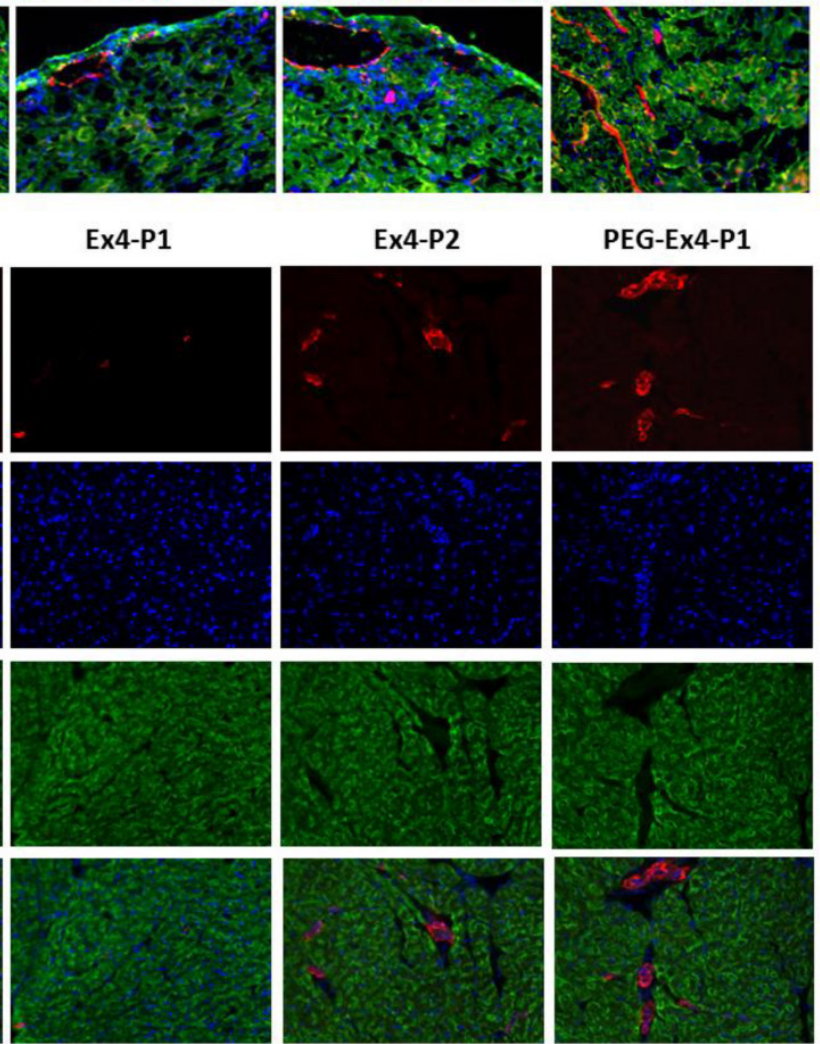

PEG-Ex4-P1
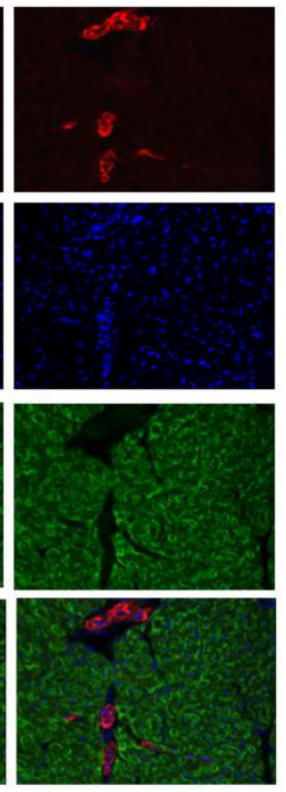

D

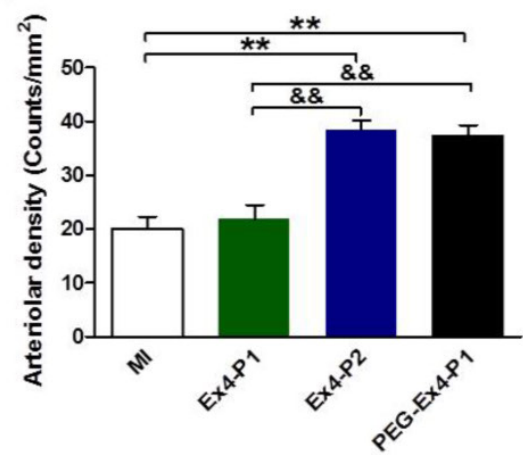

Figure 4. C40-tPEG-Ex4-Cys (PEG-Ex4) stimulates angiogenesis in post MI failing hearts. $A$ and $C, C D 31$ staining. $B$ and $D, \alpha$-smooth muscle actin staining. ${ }^{*} P<0.05$ vs. MI, ${ }^{* *} P<0.01$ vs. MI; \&P $<0.05$ vs. Ex4-PI, \&\&P $<0.01$ vs. Ex4-P1. 

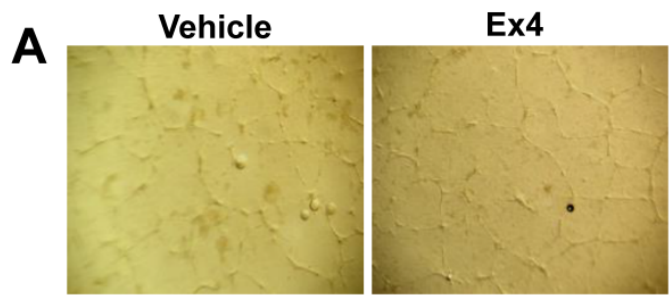

\section{PEG-Ex4}

B MI PEG-Ex4
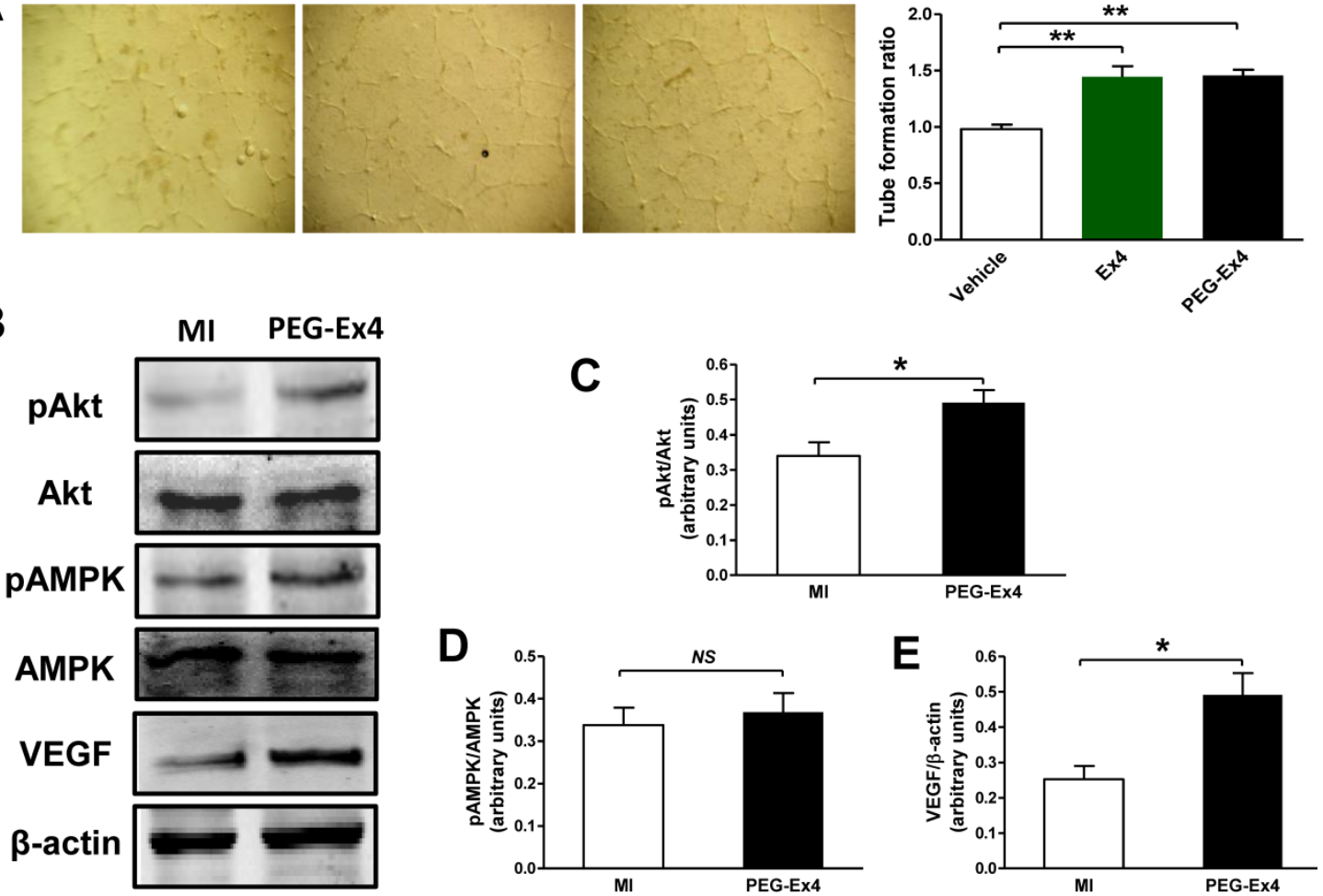

Figure 5. C40-tPEG-Ex4-Cys (PEG-Ex4) promotes tube formation and activates Akt and vascular endothelial growth factor (VEGF) in the infarct border zone. A, Tube formation assay of human umbilical vein endothelial cells (HUVEC). ${ }^{*} P<0.05$ vs. vehicle; ${ }^{* *} P<0.01$ vs. vehicle. B-E, Western blot analysis of total and phosphorylated level of Akt and AMPK as well as VEGF within cardiac tissue in the border area. ${ }^{*} P<0.05$ vs. MI.

A

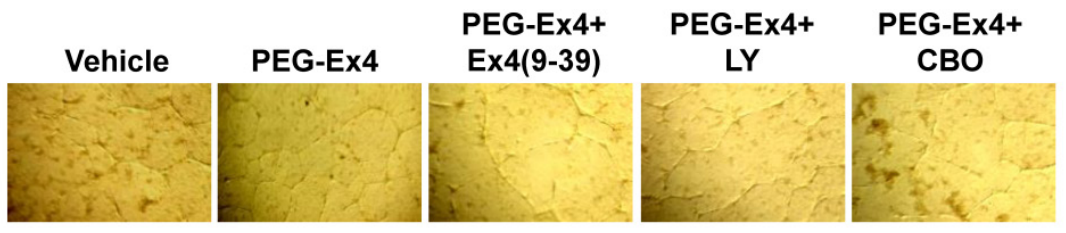

B pAkt
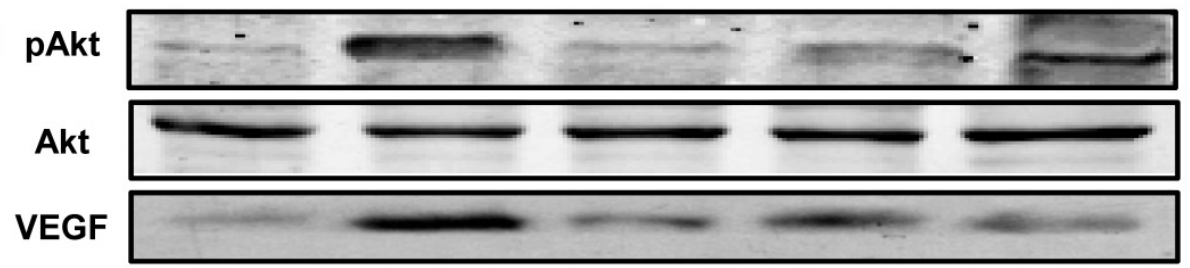

$\beta$-actin
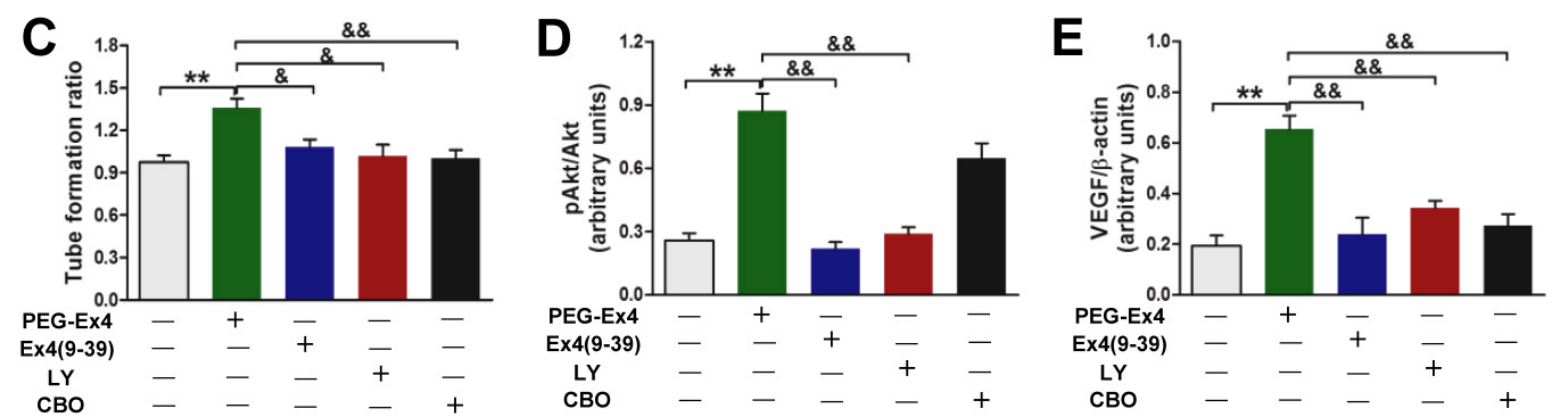

Figure 6. C40-tPEG-Ex4-Cys (PEG-Ex4) enhances tube formation via activating GLP-1R/Akt/VEGF pathway in HUVECs. A and C, Tube formation assay. B, D and E, Western blot analysis of total and phosphorylated Akt and VEGF in HUVECs. ${ }^{* *} P<0.01$ vs. vehicle; \&P $<0.05$ vs. Ex4-P1, \&\&P<0.01 vs. Ex4-P1. 
For in vivo evaluation, all the aforementioned inhibitors, including exendin-4(9-39), LY294002 and CBO-P11 were each co-administered with PEG-Ex4 in mice post MI. In accordance with the in vitro data, PEG-Ex4 was able to markedly increase Akt phosphorylation as well as VEFG level in the myocardium, which was abolished by either exendin-4(9-39) or LY294002 (Fig. 7A). Moreover, ex vivo histological evaluation showed that exendin-4(9-39) and LY294002 were both capable of attenuating the formation of new vessels stimulated by PEG-Ex4, as evidenced by reduced fluorescence intensity of both CD31 (Fig. 7B) and a-SMA (Fig. 7C) upon staining. Similar results were observed when PEG-Ex4 was co-administered with CBO-P11 (Fig. 7).

\section{Discussion}

Ischemic heart disease is the leading cause of heart failure [17]. In the past years, multiple novel medications have dramatically improved the outcome of heart failure. However, a gap is still present between current treatment success rates and those believed to be achievable [18-21].

A
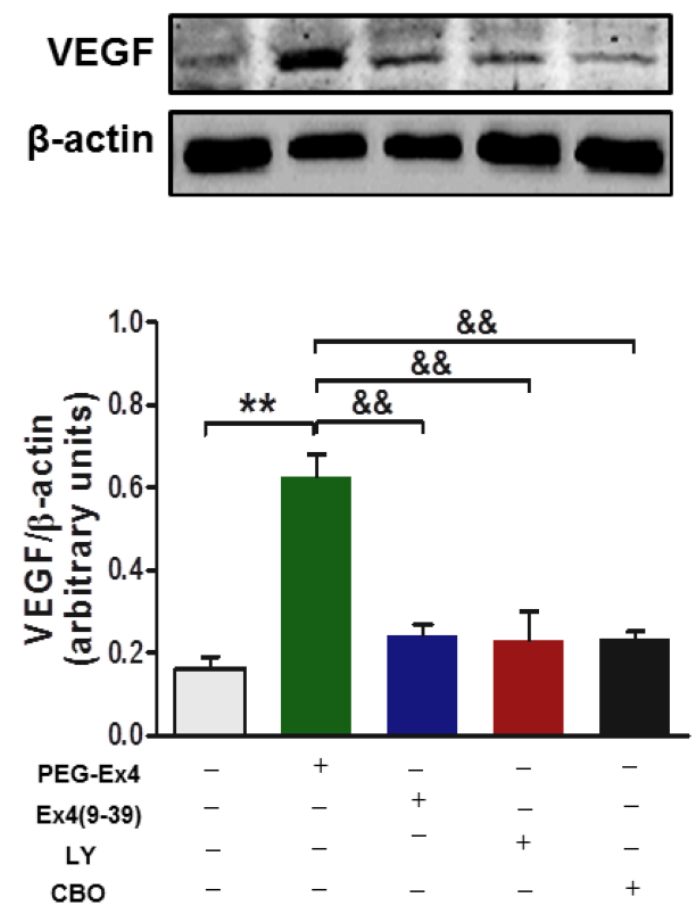

GLP-1 analog family is considered a new arrow in the quiver for heart failure management [22]. Despite of potent protection demonstrated in preclinical studies, the clinical application of GLP-1 was hindered by its extremely short half-life in vivo due to rapid break down by dipeptidyl peptidase IV. Exendin-4 is a FDA approved GLP-1 analog and has a relatively longer half-life (60 to $90 \mathrm{~min}$ ) than GLP-1 (a few minutes). However, it still requires to be injected twice daily to maintain effective blood drug concentration for the treatment of type 2 diabetes [14]. In the treatment of chronic conditions such as ischemic heart disease, this drawback certainly led to less than optimal clinical compliance and poor quality of life. In preclinical studies, exendin- 4 is able to significantly alleviate heart failure in multiple animal models [22]. However, in majority of clinical trials for heart failure treatment, exendin- 4 only provides modest benefit [23]. This discrepancy between bench and clinical studies might be partly accounted for by the less than optimal patience compliance due to the requirement of frequent injections besides different physiological factors between human and research animals.
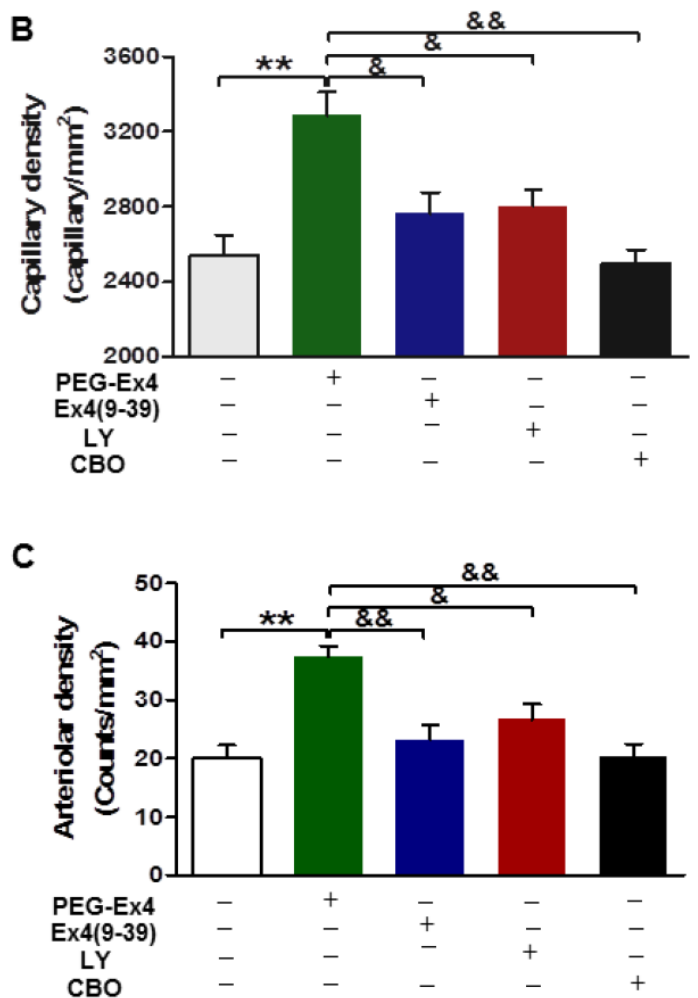

Figure 7. C40-tPEG-Ex4-Cys (PEG-Ex4) promotes angiogenesis and preserves cardiac function via activating Akt and VEGF in a GLP-1 receptor dependent manner in vivo. A, Western blot analysis of VEGF in border zone of infarct myocardium. ${ }^{* *} P<0.01$ vs. vehicle; \&\&P $<0.01$ vs. Ex4-P1. B, Capillary density measured by immunostaining for CD31 in the border region 7 days post injury. $C$, Arteriolar density measured by immunostaining for $\alpha$-smooth muscle actin in the border region 14 days after infarction. ${ }^{*} P<0.05$ vs. MI, ${ }^{* *} P<0.01$ vs. Ml; \& $P<0.05$ vs. Ex4-P1, \&\&P< 0.01 vs. Ex4-P1. 
For therapeutic peptides like exendin-4, PEGylation is a potentially effective approach to prolong their half-lives in vivo [24, 25]. PEGylation of peptides and proteins increases molecular size, shields their proteolytic sites, and masks their immunogenic sites [26]. This process can prolong in vivo pharmacokinetics, and diminish the immunogenicity of peptides and proteins, which in turn, enhances therapeutic efficacy and reduces undesirable effects over their non-PEGylated counterparts. Compared to nonspecific PEGylation, site-specific PEGylation is effective in avoiding pharmacologic heterogeneity and has higher efficiency [27-29]. In our previous study, C-terminus specifically PEGylated exendin-4 using trimeric PEG appears to have superior half-life in vivo and binding affinity to GLP-1 receptors that is comparable to unmodified exendin-4 [14]. In the present study, we tested its effectiveness in a mouse model of MI. PEG-Ex4 administered at much lower frequency than its unmodified parental molecule produced similar extent of benefit as demonstrated by multiple indexes, suggesting that our site-specifically PEGylated exendin- 4 not only prolonged the in vivo half-life but also significantly enhanced the longevity of its therapeutic effect.

Stimulated de novo formation of microvessels, also known as angiogenesis [30], has the potential to eradicate the imbalance of supply and demand via enhanced oxygen and nutrition delivery and is essential to prevent the transition to heart failure [31]. Improved angiogenesis has been suggested to be the key mechanism mediating the effects of GLP-1. In pressure overload induced chronic heart failure, increase of GLP-1 level induced by dipeptidyl peptidase- 4 inhibition is found to be associated with stimulated angiogenesis in myocardium [32]. In the present study, we for the first time demonstrated that PEG-Ex4 treated hearts had a significantly higher capillary and arteriole density in the border zone of infarct myocardium, suggesting enhanced compensatory angiogenesis. Endothelial cells play a central role in angiogenesis and also has abundant GLP-1 receptor expression [33]. In our report, PEG-Ex4 increased tube formation of cultured HUVECs, suggesting that angiogenesis induced by PEG-Ex4 might be mediated through its direct effect on endothelial cells.

Among many different growth factors implicated in angiogenesis, VEGF is the most intensively investigated one and is the key cytokine mediating endothelial cell proliferation and angiogenesis. Exogenous administration of VEGF via stem cell delivery and gene manipulation has been shown to increase angiogenesis in ischemic myocardium [34]. However, these approaches require complicated lab work and carry risks such as pathogen transmission, oncogene- sis, etc. In the present study, PEG-Ex4 increased VEGF level in both failing heart induced by MI and cultured HUVECs while VEGF inhibition abolished the survival and functional benefit of PEG-Ex4 treatment and increase of tube formation, confirming that PEG-Ex4 increases VEGF production by endothelial cells and this effect plays a key role in mediating the cardioprotection of PEG-Ex4.

Akt is well known for its pivotal role in mediating cell survival. GLP-1 receptor agonist has been shown to activate Akt in heart subjected to I/R injury. Akt has also been shown to mediate increased endothelial cell proliferation by GLP-1 in vitro [35]. In the present study, PEG-Ex4 increased Akt phosphorylation in heart subjected to MI and cultured HUVECs while Akt inhibition abolished the cardioprotection in vivo and endothelial cell tube formation in vitro afforded by PEG-Ex4. All these results support the notion that Akt is the key intracellular signaling molecule that mediates the protection of PEG-Ex4.

Taken together, these results suggest that PEG-Ex4 promotes angiogenesis after MI possibly through the activation of GLP-1R/Akt/VEGF pathway in endothelial cells, which in turn, mediates the cardioprotective action of PEG-Ex4 in chronic ischemic heart disease.

It is of note that in this study the evaluation of cardiac function and geometry change were performed by echocardiography using mid myocardium short axis images. It is less accurate than some more advanced modalities such as 2 chamber and 4 chamber views of echocardiography combined with the use of Simpson's rule and cardiac MRI. In the present study, PEG-Ex4 treatment were started 3 days after MI to achieve maximal therapeutic effect while in typical clinical scenario, therapy is usually started when heart failure is fully developed. In our future study, the effectiveness of PEG-Ex4 in a fully developed chronic heart failure model will be tested.

\section{Conclusion}

In the present study, we provide compelling evidences that PEG-Ex4, a novel long circulating exendin-4 analog confers significant cardioprotective effect in heart failure induced by MI. Its benefit is at least partially mediated by angiogenesis induced by activation of GLP-1R/Akt/VEGF pathway in endothelial cells. These data identify PEG-Ex4 as an excellent candidate for treating ischemic heart failure. More clinically relevant studies are warranted in the near future.

\section{Abbreviations}

AAR: area at risk; $\mathrm{CHF}$, chronic heart failure; DPP4: dipeptidyl peptidase-4; Ex4: exendin-4; FDA: 
Food and Drug Administration; GLP-1: glucagon-like peptide-1; GLP-1R: glucagon- like peptide-1 receptor; INF: area of infarct; LV: left ventricular; LVEDD: left ventricular end diastolic diameter; LVESD: left ventricular end systolic diameter; LVFS: left ventricular fraction shortening; MI: Myocardial infarction; PEG-Ex4: PEGylated exendin-4; a-SMA: a-smooth muscle actin.

\section{Acknowledgments}

This study was supported by the National Nature Science Foundation of China (NO. 81400366), Xijing Research Boosting Program (NO. XJZT13M11), and the Intramural Research Program (IRP), National Institute of Biomedical Imaging and Bioengineering (NIBIB), National Institutes of Health (NIH).

\section{Competing Interests}

The authors have declared that no competing interest exists.

\section{References}

1. Drucker DJ. The biology of incretin hormones. Cell Metab. 2006; 3: 153-65.

2. Moberly SP, Mather KJ, Berwick ZC, Owen MK, Goodwill AG, Casalini ED, et al. Impaired cardiometabolic responses to glucagon-like peptide 1 in obesity and type 2 diabetes mellitus. Basic Res Cardiol. 2013; 108: 365.

3. Li Y, Hansotia T, Yusta B, Ris F, Halban PA, Drucker DJ. Glucagon-like peptide-1 receptor signaling modulates beta cell apoptosis. J Biol Chem. 2003; 278 : $471-8$.

4. Grieve DJ, Cassidy RS, Green BD. Emerging cardiovascular actions of the incretin hormone glucagon-like peptide-1: potential therapeutic benefits beyond glycaemic control? Br J Pharmacol. 2009; 157: 1340-51.

5. Ban K, Noyan-Ashraf MH, Hoefer J, Bolz SS, Drucker DJ, Husain M. Cardioprotective and vasodilatory actions of glucagon-like peptide 1 receptor are mediated through both glucagon-like peptide 1 receptor-dependent and -independent pathways. Circulation. 2008; 117: 2340-50.

6. Noyan-Ashraf MH, Momen MA, Ban K, Sadi AM, Zhou YQ, Riazi AM, et al. GLP-1R agonist liraglutide activates cytoprotective pathways and improves outcomes after experimental myocardial infarction in mice. Diabetes. 2009; 58 : 975-83.

7. Liu FQ, Zhang XL, Gong L, Wang XP, Wang J, Hou XG, et al. Glucagon-like peptide 1 protects microvascular endothelial cells by inactivating the PARP-1/iNOS/NO pathway. Mol Cell Endocrinol. 2011; 339: 25-33.

8. Anagnostis P, Athyros VG, Adamidou F, Panagiotou A, Kita M, Karagiannis A, et al. Glucagon-like peptide-1-based therapies and cardiovascular disease: looking beyond glycaemic control. Diabetes Obes Metab. 2011; 13: 302-12.

9. Goke R, Fehmann HC, Linn T, Schmidt H, Krause M, Eng J, et al. Exendin-4 is a high potency agonist and truncated exendin-(9-39)-amide an antagonist at the glucagon-like peptide 1-(7-36)-amide receptor of insulin-secreting beta-cells. J Biol Chem. 1993; 268: 19650-5.

10. Timmers L, Henriques JP, de Kleijn DP, Devries JH, Kemperman H, Steendijk $\mathrm{P}$, et al. Exenatide reduces infarct size and improves cardiac function in a porcine model of ischemia and reperfusion injury. J Am Coll Cardiol. 2009; 53: $501-10$

11. Teramoto S, Miyamoto N, Yatomi K, Tanaka Y, Oishi H, Arai H, et al. Exendin-4, a glucagon-like peptide-1 receptor agonist, provides neuroprotection in mice transient focal cerebral ischemia. J Cereb Blood Flow Metab. 2011; 31: 1696-705.

12. Bao W, Aravindhan $\mathrm{K}$, Alsaid $\mathrm{H}$, Chendrimada $\mathrm{T}$, Szapacs $\mathrm{M}$, Citerone DR, et al. Albiglutide, a long lasting glucagon-like peptide- 1 analog, protects the rat heart against ischemia/reperfusion injury: evidence for improving cardiac metabolic efficiency. PloS one. 2011; 6: e23570.

13. Sauve M, Ban K, Momen MA, Zhou YQ, Henkelman RM, Husain M, et al. Genetic deletion or pharmacological inhibition of dipeptidyl peptidase-4 improves cardiovascular outcomes after myocardial infarction in mice. Diabetes. 2010; 59: 1063-73.

14. Kim TH, Jiang HH, Lim SM, Youn YS, Choi KY, Lee S, et al. Site-specific PEGylated Exendin-4 modified with a high molecular weight trimeric PEG reduces steric hindrance and increases type 2 antidiabetic therapeutic effects. Bioconjug Chem. 2012; 23: 2214-20.

15. Zhang XX, Sun Z, Guo J, Wang Z, Wu C, Niu G, et al. Comparison of (18)F-labeled CXCR4 antagonist peptides for PET imaging of CXCR4 expression. Mol Imaging Biol. 2013; 15: 758-67.
16. Sun Z, Tong G, Ma N, Li J, Li X, Li S, et al. NDRG2: a newly identified mediator of insulin cardioprotection against myocardial ischemia-reperfusion injury. Basic Res Cardiol. 2013; 108: 341.

17. Go AS, Mozaffarian D, Roger VL, Benjamin EJ, Berry JD, Blaha MJ, et al. Heart disease and stroke statistics--2014 update: a report from the American Heart Association. Circulation. 2014; 129: e28-e292.

18. Viswanathan M, Golin CE, Jones CD, Ashok M, Blalock SJ, Wines RC, et al Interventions to improve adherence to self-administered medications for chronic diseases in the United States: a systematic review. Ann Intern Med. 2012; 157: 785-95.

19. Osterberg L, Blaschke T. Adherence to medication. N Engl J Med. 2005; 353: 487-97.

20. Peterson AM, Takiya L, Finley R. Meta-analysis of trials of interventions to improve medication adherence. Am J Health Syst Pharm. 2003; 60: 657-65.

21. Dunbar-Jacob J, Erlen JA, Schlenk EA, Ryan CM, Sereika SM, Doswell WM. Adherence in chronic disease. Annu Rev Nurs Res. 2000; 18: 48-90.

22. Zhao TC. Glucagon-like peptide-1 (GLP-1) and protective effects in cardiovascular disease: a new therapeutic approach for myocardial protection. Cardiovasc Diabetol. 2013; 12: 90

23. Munaf M, Pellicori P, Allgar V, Wong K. A meta-analysis of the therapeutic effects of glucagon-like Peptide-1 agonist in heart failure. Int J Pept. 2012; 249827.

24. Kang JS, Deluca PP, Lee KC. Emerging PEGylated drugs. Expert Opin Emerg Drugs. 2009; 14: 363-80.

25. Milla P, Dosio F, Cattel L. PEGylation of proteins and liposomes: a powerful and flexible strategy to improve the drug delivery. Curr Drug Metab. 2012; 13: 105-19.

26. Youn YS, Na DH, Yoo SD, Song SC, Lee KC. Carbohydrate-specifically polyethylene glycol-modified ricin A-chain with improved therapeutic potential. Int J Biochem Cell Biol. 2005; 37:1525-1533.

27. Yamamoto Y, Tsutsumi Y, Yoshioka Y, Nishibata T, Kobayashi K, Okamoto T, et al. Site-specific PEGylation of a lysine-deficient TNF-alpha with full bioactivity. Nat Biotechnol. 2003; 21: 546-52.

28. Moreadith RW, Collen D. Clinical development of PEGylated recombinant staphylokinase (PEG-Sak) for bolus thrombolytic treatment of patients with acute myocardial infarction. Adv Drug Deliv Rev. 2003; 55: 1337-45.

29. Rosendahl MS, Doherty DH, Smith DJ, Carlson SJ, Chlipala EA, Cox GN. A long-acting, highly potent interferon alpha-2 conjugate created using site-specific PEGylation. Bioconjug Chem. 2005; 16: 200-7.

30. Kanzler I, Tuchscheerer N, Steffens G, Simsekyilmaz S, Konschalla S, Kroh A, et al. Differential roles of angiogenic chemokines in endothelial progenitor cell-induced angiogenesis. Basic Res Cardiol. 2013; 108: 310.

31. Eapen Z, Rogers JG. Strategies to attenuate pathological remodeling in heart failure. Curr Opin Cardiol. 2009; 24: 223-9.

32. Shigeta T, Aoyama M, Bando YK, Monji A, Mitsui T, Takatsu M, et al. Dipeptidyl peptidase-4 modulates left ventricular dysfunction in chronic heart failure via angiogenesis-dependent and -independent actions. Circulation. 2012; 126: 1838-51.

33. Sjoholm A. Impact of glucagon-like peptide-1 on endothelial function. Diabetes Obes Metab. 2009; 11 Suppl 3: 19-25.

34. Lavu M, Gundewar S, Lefer DJ. Gene therapy for ischemic heart disease. J Mol Cell Cardiol. 2011; 50: 742-50.

35. Lehrke M, Marx N. Cardiovascular effects of incretin-based therapies. Rev Diabet Stud. 2011; 8: 382-91. 